REVIEW

\title{
Approach to the patient with epilepsy in the outpatient department
}

\author{
S Hadjikoutis, P E M Smith
}

Postgrad Med J 2005;81:442-447. doi: 10.1136/pgmj.2004.029298

Epilepsy is common and serious (prevalence 750 per 100000 ) and has an impact upon employment, education, and driving. The diagnosis requires a detailed history including witness account. Clinicians must distinguish seizures particularly from syncope and psychogenic attacks. Electroencephalography and magnetic resonance brain scanning help to identify causes and classification of epilepsy, but alone rarely provide the diagnosis. Antiepileptic drug treatment is required long term and is potentially hazardous; patients should start treatment only after informed discussion with an epilepsy specialist. Patients require reliable written information, particularly the driving regulations, and the impact of seizures on employment, education, and leisure. Women must understand the potential drug teratogenic effects. Certain patient groups benefit from targeted epilepsy services, for example, learning disabled, children, teenagers, and elderly. People with epilepsy require long term specialist follow up. Although this is currently provided in mainly in secondary care (including nurse led clinics), improved liaison with primary care should enable improved access to epilepsy services. Epilepsy care should be multidisciplinary and long term, linking primary and secondary care, and empowering patients towards improved management of their condition.

See end of article for authors' affiliations

Correspondence to: Dr P E M Smith, The Epilepsy Unit, University Hospital of Wales, Heath Park, Cardiff CF14 4XW UK; SmithPE@cardiff.ac.úk

Submitted

30 September 2004

Accepted 1 December 2004
E pileptology has changed from a "Cinderella"

E specialty to arguably the most exciting area of neurology. We now have a range of effective antiepileptic drugs, high quality imaging identifying a structural basis for most adult onset epilepsy, and an increasing public awareness of epilepsy and its problems. What is still lacking is the number of specialists needed to deliver an essentially clinical and supportive service for a long term disorder affecting almost $1 \%$ of the population. Guidance from the National Institute for Health and Clinical Excellence (NICE) on the diagnosis and management of the epilepsies ${ }^{1}$ offers national standards for epilepsy care and will help to highlight and correct current deficiencies in provision of epilepsy care.

\section{EPILEPSY CLINICS}

Epilepsy is the commonest serious neurological condition after stroke (prevalence 750 per
$100000)$; the workload of its management is potentially huge. However, most patients become seizure free with antiepileptic drugs and can live normal lives, but $30 \%$ have continued seizures or significant drug side effects, or both; these require regular epilepsy clinic review. Epilepsy incidence is 50 per 100000 people per year. However, for each person diagnosed with epilepsy, four to five people with blackouts must be assessed; thus 250 per 100000 people require specialist assessment.

Three patient groups attend epilepsy clinics:

- Patients for review, usually but not always with epilepsy.

- New patients with undiagnosed blackouts (seizure, syncope, or psychogenic), who need urgent (within two weeks) specialist assessment.

- New patients with an epilepsy diagnosis (not necessarily correct) with particular issues, who need detailed reappraisal.

\section{HISTORY}

Diagnosing episodic changes in consciousness requires a general medical perspective, an understanding of the differential diagnosis, and knowledge of seizure and epilepsy classification. A suitably experienced clinician must take a detailed history, including a witness account. There is no short cut, making blackout diagnosis a time consuming activity. Investigations such as electroencephalogram (EEG) and magnetic resonance (MR) brain scanning can support the clinical diagnosis, but generally the history is crucial. Where there is doubt (this is common), re-taking the history is more helpful than repeating tests.

\section{Key components}

The history should focus on precipitants (situation and trigger), warning (prodrome), the episode, and the symptoms that follow (recovery).

Table 1 lists characteristics helpful in distinguishing the common causes of blackouts: syncope, seizures, and psychogenic episodes; other transient episodes include migraine, transient ischaemic attacks, and movement disorders. ${ }^{2}$ The clinician must next decide whether the seizure was provoked or unprovoked, the first (single) seizure or part of a recurrent tendency

Abbreviations: AED, antiepileptic drug; EEG, electroencephalogram; CT, computed tomography; MRI, magnetic resonance imaging 
Table 1 History points distinguishing syncope, seizures, and psychogenic episodes. Note the syncope features here relate to vasovagal syncope: cardiac syncope (even when tachycardia related) may occur abruptly and without prodrome

\begin{tabular}{|c|c|c|c|}
\hline & Syncope & Seizure & Psychogenic episode \\
\hline Trigger & $\begin{array}{l}\text { Common (upright, } \\
\text { bathroom, blood) }\end{array}$ & $\begin{array}{l}\text { Rare (flashing lights, } \\
\text { hyperventilation) }\end{array}$ & Common (anger, panic) \\
\hline Prodrome & Almost always & Common (aura) & Uncommon (anxiety symptoms) \\
\hline Onset & Gradual & Usually sudden & Often gradual \\
\hline Duration & $1-30$ seconds & $1-3$ minutes & Often prolonged (occasionally hours) \\
\hline Colour & Very pale & Cyanosed & Usually normal \\
\hline Convulsions & Common (brief) & Common (prolonged) & $\begin{array}{l}\text { Atypical (fighting, pelvic thrusting, } \\
\text { erratic movements) }\end{array}$ \\
\hline Eyes closed & Often & Less common & $\begin{array}{l}\text { Common (resisting eye opening and eye } \\
\text { contact) }\end{array}$ \\
\hline Incontinence & Uncommon & Common & Uncommon \\
\hline $\begin{array}{l}\text { Lateral tongue } \\
\text { bite }\end{array}$ & Rare & Common & $\begin{array}{l}\text { Very rare (may bite front of tongue or } \\
\text { cheek) }\end{array}$ \\
\hline Breathing & Quiet & Apnoea (expiration) & Hyperventilation or apnoea (inspiration) \\
\hline $\begin{array}{l}\text { Post-ictal } \\
\text { confusion }\end{array}$ & Rare & Common & Rare \\
\hline Recovery & Rapid (wakes on floor) & $\begin{array}{l}\text { Slow (wakes in } \\
\text { ambulance) }\end{array}$ & $\begin{array}{l}\text { Variable (repeated episodes, may be } \\
\text { tearful) }\end{array}$ \\
\hline Self injury & Rare & Common & Uncommon (carpet burn, wrist injury) \\
\hline
\end{tabular}

(epilepsy), and its classification (focal or generalised, idiopathic or symptomatic).

\section{Provoked or unprovoked?}

Provoked (acute symptomatic) seizures occur with transient cerebral insults. Examples include alcohol withdrawal, drug intoxication, meningitis/encephalitis, head injury, and intracerebral haemorrhage. Long term antiepileptic drug treatment is usually not needed for these.

\section{Single seizure or epilepsy?}

Most people with epilepsy are diagnosed after a major seizure, but often have had preceding minor events. People may not consider myoclonic jerks, absence seizures, simple or even complex partial seizures to have been epileptic events, and so they go unreported.

\section{Classification}

Seizures are either generalised or focal.

- Primarily generalised seizures include typical absences (abrupt onset and offset, $3 \mathrm{~Hz}$ spike and wave on EEG, usually normal intellect), myoclonic jerks, and generalised tonic-clonic seizures.

- Focal (partial onset) seizures include déjà vu or epigastric aura of medial temporal lobe epilepsy, head and eye turning (adversive seizure) of frontal lobe epilepsy, or visual aura of occipital epilepsy. Generalised tonic-clonic seizures in adults are usually secondarily generalised.

Epilepsies are classified as generalised or focal (localisation related) according to the predominant seizure type, but also takes note of the possible underlying cause:

- Idiopathic epilepsies typically have age specific onset (child or adolescent), favourable response to antiepileptic drugs (AEDs), normal cerebral imaging, and a presumed genetic aetiology. Idiopathic generalised epilepsies (for example, juvenile myoclonic epilepsy) comprise 30\% of epilepsies and present with combinations of generalised seizures.

- Symptomatic epilepsies have a known underlying cause (usually structural), such as mesial temporal sclerosis (fig 1), tumour or cortical dysplasia. They mainly have focal seizures, often resistant to drug treatment. Cryptogenic epilepsies have a presumed symptomatic cause, but a definite explanation cannot be found (usually normal imaging).

\section{Drug treatment history}

This should include:

- Current and previous AEDs, including dose, formulation, dates, benefit, and adverse effects.

- Potentially epileptogenic drugs, for example, ciprofloxacin, tramadol, antimalarials.

- Drugs with important AED interactions, for example, warfarin, digoxin, oral contraceptive.

\section{Medical history}

Previous blackout events must be explored in detail and patients asked specifically for any history of absences, myoclonus, or photosensitivity. The history should include potential cerebral insults, for example, premature and/or traumatic birth, febrile seizures, meningitis/encephalitis, and

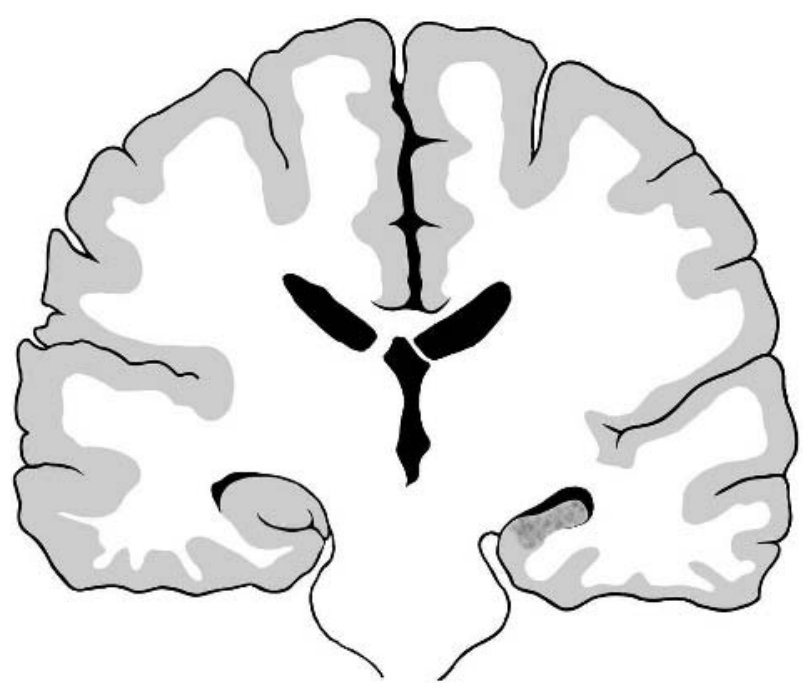

Figure 1 Schematic brain section illustrating left sided mesial temporal sclerosis. Note asymmetry of hippocampi, temporal lobes/cortex, and fornices. 
head injury. Heart disease (congenital or acquired) may suggest syncope. Depression and anxiety commonly accompany epilepsy, but significant psychiatric history (including misuse and illicit drug dependence) might favour psychogenic seizures.

\section{Family history}

The family history should include epilepsy, febrile seizures, syncope, and sudden unexpected death. Family histories are notoriously unreliable, incomplete, sometimes deliberately concealed, and may require repeated inquiry or even direct assessment of affected people.

\section{Social history}

This includes education, employment, driving status, family planning, home situation, sporting interests, use of alcohol and illicit drugs.

\section{EXAMINATION}

Physical examination contributes surprisingly little to blackout diagnosis.

- Epilepsy: examination includes a search for skin stigmata (neurofibromatosis, tuberous sclerosis), dysmorphic features, body size asymmetry (for example, nail size), and cerebral bruit. Long term AEDs may result in tremor, hair loss, weight gain (for example, sodium valproate, gabapentin), gum hypertrophy, hirsutism, acne, ataxia, or absent reflexes (for example, phenytoin). Patients with focal onset seizures require examination for visual field defects or long tract signs. Field defects from vigabatrin therapy or temporal lobe epilepsy surgery may have implications for driving, even when seizure free.

- Probable syncope: cardiovascular examination is essential, particularly in the elderly patient.

- Psychcogenic episodes: 25\% of patients with unexplained blackouts have panic disorder and hyperventilation. It can be helpful (to patient and clinician) to provoke the physical symptoms of hyperventilation in the clinic by deep breathing for three minutes. Hyperventilation may also induce typical absences in children. It is worth looking for wrist scars (previous self harm) and needle marks as predictors of psychogenic episodes.

\section{INVESTIGATIONS}

All first seizures must be explained and usually investigated. "Everyone is allowed one seizure" is nonsense and potentially dangerous. Note however that normal EEG and brain scan does not exclude epilepsy.

EEG can help to distinguish generalised from focal epilepsies (fig 2), support an epilepsy syndrome diagnosis, and localise the focus of partial seizures. However, it is normal in about $60 \%$ of people after a single seizure and in about $40 \%$ with epilepsy. EEGs are at their most useful soon after the seizure and before AEDs are prescribed. EEGs are used to support clinical suspicion rather than as the sole means of making the diagnosis of epilepsy. Uncritical interpretation of EEG by those unaware of its limitations presents dangers of erroneous diagnosis of epilepsy, unnecessary restrictions, stigma, and long term treatment. Prolonged video EEG however may capture typical episodes and is particularly helpful in distinguishing epileptic from non-epileptic episodes.

Brain imaging is indicated for spontaneous seizures either of presumed focal onset (aura, focal signs, or EEG focus) or refractory to medical treatment. Spontaneous seizures arising in adults are mostly focal and so all should be considered for cerebral imaging. MRI is the modality of choice because computed tomography (CT) often misses epilepsy causes such as mesial temporal sclerosis (fig 1), cortical dysplasia, cavernoma, and benign temporal lobe tumours, for example, ganglioglioma, dysembryoplastic neuroepithelial tumour. ${ }^{3}$

Electrocardiogram (ECG): 12 lead ECG is indicated after all undiagnosed blackouts, especially suspected syncope and in the elderly patient. Rare cardiac causes of syncope (long QT, Brugada syndrome) mimic epilepsy and can induce sudden death. ${ }^{4}$ Investigation of suspected syncope follows standard guidelines, ${ }^{5}$ and includes ECG, exercise testing, head up tilt table testing, and 24 hour ECG. Suspected cardiogenic syncope requires urgent cardiology referral.

\section{MANAGEMENT}

\section{Starting drug treatment}

AEDs are considered usually after more than one spontaneous epileptic seizure. The MESS study, ${ }^{6}$ compared immediate with delayed treatment after single seizures and early epilepsy, and showed that 14 patients were randomised to treatment to prevent one patient relapsing by two years. Long term drug treatment is therefore usually withheld after a single seizure. However, highly epileptogenic causes such as glioma, justify AEDs after a single event.

AED treatment is usually long term, requiring informed discussion with an epilepsy specialist. Short term AED trials are rarely justified. The patient must balance the seizure morbidity (including the small risk of sudden unexpected death $(\text { SUDEP })^{7}$ ) against the consequences, inconvenience, and the adverse effects for that person (including potential teratogenicity).

\section{Choosing AEDs}

The 2004 England and Wales NICE guidelines on the use of new AEDs $^{8}$ advise initially either carbamazepine (focal seizures) or sodium valproate (focal or generalised seizures).
A

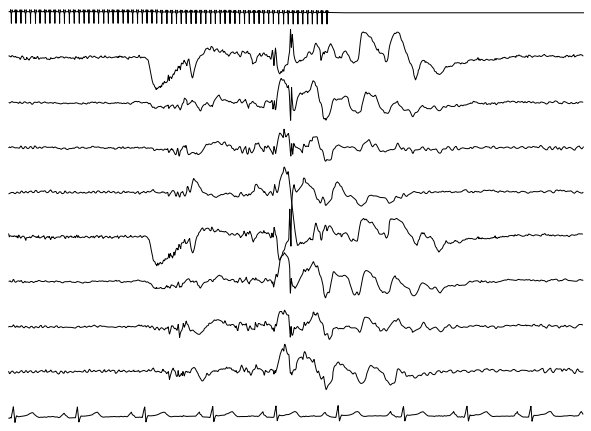

B

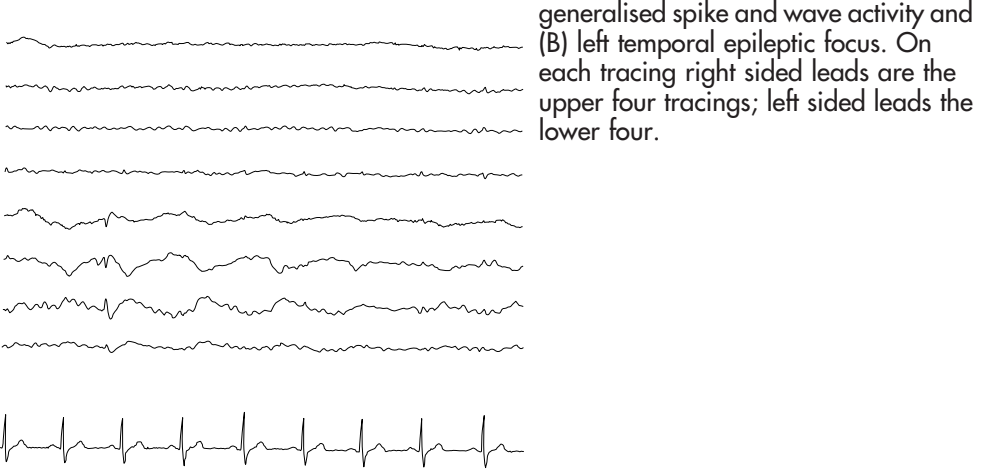


Women of childbearing potential (including girls requiring AED into their childbearing years) should probably not be prescribed valproate as first line treatment because of teratogenicity. ${ }^{9}$ Lamotrigine seems a safer alternative. ${ }^{10}$ Alternative monotherapy should be tried before considering polytherapy. ${ }^{11}$ Vigabatrin is no longer started (except in babies with West syndrome) because of problems with permanent visual field constriction. The role of some of the newer drugs (gabapentin, levetiracetam, oxcarbazepine, pregabalin, tiagabine, topiramate) will become clearer after SANAD, ${ }^{12}$ a large randomised controlled study comparing first line monotherapy with new and conventional AEDs.

\section{Stopping AEDs}

Seizure free patients require detailed discussion before stopping AEDs. In children it is usual to try after two years seizure free. In adults, continued seizure freedom for driving and employment often justifies the inconvenience of continued drug treatment; many adults therefore continue taking AEDs while seizure free for years. Women wishing to conceive naturally want to stop AEDs (see below), and often do so without consulting their doctor. ${ }^{13}$ Overall, $40 \%$ of adults seizure free for two years will relapse. ${ }^{14}$ The risk is highest with previous tonic-clonic or myoclonic seizures, seizures after starting AEDs, needing more than one AED, and in those with abnormal EEGs. ${ }^{15}$ The greater likelihood of seizures in the months after withdrawal ${ }^{16}$ is reflected in the UK Driver and Vehicle Licensing Agency's (DVLA) advice to stop driving from the start of AED withdrawal until six months after its completion.

\section{Surgery}

Symptomatic epilepsies, for example, from mesial temporal sclerosis, are commonly resistant to AEDs and justify consideration of surgery. ${ }^{17}$ Epilepsy surgery is generally underused in the UK. ${ }^{18}$ The detailed preparation for surgery (prolonged and sometimes invasive video EEG monitoring, sodium amytal testing) is available in only a few centres. Potentially curative procedures include removal of confirmed epileptogenic lesions including temporal lobectomy for mesial temporal sclerosis; palliative procedures include multiple subpial transection, corpus callosotomy, and hemispherectomy in patients with severe symptomatic epilepsies. ${ }^{19}$ Vagus nerve stimulation is an option for adults and children ${ }^{20}$ with resistant epilepsy.

\section{SPECIAL SITUATIONS \\ Refractory epilepsy}

Refractory focal epilepsy demands a detailed search for structural abnormality. Not all MR scans are equal in their quality of data acquisition or reporting (ideally brain MRI should include high definition, thin sliced images, with FLAIR sequences, and reported by a neuroradiologist); repeat imaging may be necessary. Poor treatment compliance may cause apparently refractory epilepsy. Furthermore, 15\% of patients with "refractory epilepsy" have only psychogenic seizures. ${ }^{21}$ Patients who have not responded to two first line AEDs therefore require careful diagnostic review. The epilepsy classification must also be reviewed as certain AEDs beneficial to focal epilepsies (for example, carbamazepine, gabapentin) may be ineffective, and even worsen absences, myoclonus, and photosensitivity.

\section{Learning disability}

A third of patients with severe learning disability have epilepsy. Such consultations can be very challenging. Again the history is crucial and so a carer who knows the patient well must accompany the patient. As far as practical, the conversation should be directed at the patient rather than carers. Close liaison with the community learning disabilities team is essential.

\section{Children and teenagers}

Epilepsy in children is an important subspecialty, not covered by this review. Teenagers with epilepsy can benefit from combined consultations with adult and paediatric specialists to tackle their complex medical and social problems. ${ }^{22}$

\section{Elderly patients}

Blackouts management in the elderly patient is complicated for several reasons. Patients often live alone (no witness account), may have poor recall of events, and other medical problems with pre-existing polypharmacy. Most importantly, both epilepsy and syncope are commoner in the elderly population, but syncope presenting in old age requires urgent cardiological evaluation. Cerebrovascular disease is closely linked to elderly onset epilepsy; such patients require consideration of antiplatelet and statin treatment, as well as AED. ${ }^{23}$ There is little evidence to support any particular AED in the elderly patient; in general AEDs with renal excretion and fewer interactions are preferred.

\section{Pregnancy}

Young women need clear information upon which to base treatment and lifestyle decisions (see below). However, for women already pregnant, teratogencity advice comes too late. Epilepsy nurse input into antenatal clinics helps management of epilepsy in pregnancy (about $0.5 \%$ of all pregnancies). Combined neurologist and obstetrician clinics are useful for complicated cases.

\section{Syncope}

Syncope affects $22 \%$ of the population ${ }^{24}$; and presents potentially an enormous problem. Although only a few are referred to specialists (mainly cardiologists), syncope is still the commonest diagnosis among new referrals to an epilepsy clinic. Epilepsy specialists must therefore work closely with cardiologists, preferably in a joint "blackout" clinic.

\section{Psychogenic episodes}

The scarcity of local liaison psychiatry services means that patients with psychogenic seizures are often followed up in epilepsy clinics, becoming major users of epilepsy services. Ideally, one specialist should supervise their management (including sustained AED withdrawal) using regular short interval follow up and admissions only under that specialist's care. Without this, patients risk admission as "known epileptic" and their AED restarted or increased.

\section{INFORMATION FOR PATIENTS \\ Driving}

Loss of driving privileges contributes significantly to the social predicament of epilepsy. Many people are told that they cannot drive until seeing the specialist, and eagerly await advice. After an unprovoked epileptic seizure (or undiagnosed blackout), UK drivers must stop, inform the DVLA, ${ }^{25}$ and remain seizure free for a year before regaining their licence. This law applies even to minor seizures including epileptic myoclonic jerks. Provoked seizures, for example, within a week of head injury, are dealt with individually by the DVLA. For heavy goods and public service licences, drivers must be seizure free for 10 years and off drug treatment.

\section{Lifestyle}

People with epilepsy should be encouraged to live normal lives, within sensible limits.

Sports and leisure: the seizure frequency and type influence advice for specific circumstances such as 
swimming, cycling on busy roads, and isolation sports (for example, horse riding, hill walking, etc).

Alcohol may provoke seizures through sleep loss, AED interaction (long term alcohol intake induces liver enzymes), forgetting to take AEDs, or inducing misplaced confidence that AEDs can be omitted. Pragmatic advice is that patients with epilepsy should limit alcohol consumption to four units in 24 hours.

Sleep deprivation is an avoidable cause of lowered seizure threshold, especially in idiopathic generalised epilepsies.

Flashing lights: true photosensitivity is uncommon in adults especially while taking AEDs, but many people with epilepsy misguidedly avoid computers, televisions, and discos.

\section{Teratogenicity}

Women contemplating pregnancy require balanced and reliable information about the teratogenic potential of their AED. Unfortunately, such data are currently lacking and advice is based to an extent upon opinion and conjecture. Nevertheless, prospective observational data from the UK Epilepsy and Pregnancy Register ${ }^{9}$ show valproate to be associated with major congenital malformations more than either carbamazepine or lamotrigine. The risks, although multifactorial, relate to AED burden: monotherapy $4 \%-6 \%$, duotherapy $7 \%-8 \%$, and polytherapy $15 \%-20 \%{ }^{26}$ Furthermore, there are suggestions, awaiting prospective evaluation, of increased neuro-developmental delay among children exposed to AEDs in utero. ${ }^{27}$ Unfortunately valproate is the AED of first choice for idiopathic generalised epilepsies and so changing drugs to protect unborn children risks compromising seizure control. Also, switching from valproate to lamotrigine is complicated, taking several months. Despite the absence of conclusive proof and the inherent difficulties in researching this area, ${ }^{28}$ young women, particularly taking valproate, require specialist review to inform decisions about long term treatment.

\section{FOLLOW UP}

Epilepsy, more than many chronic disorders, justifies long term follow up. The diagnosis is history based and too often is made incorrectly, particularly in non-specialist hands. ${ }^{29}$ The choice and need for prescribed AEDs may be inappropriate, and patients may too easily accept drug side effects and unnecessary lifestyle restrictions. Good practice would suggest annual review, including in "nurse led" epilepsy specialist clinics, be offered to all patients with epilepsy. Proactive specialist review of those currently managed in the community may also be justified to check diagnoses, optimise clinical management, and to provide information. ${ }^{30}$

\section{AND FINALLY...}

Patients need opportunities to ask questions. "What would you like to ask?" induces more response than "Do you have any questions?" Early follow up after the initial diagnosis provides the opportunity to discuss concerns after a period of reflection. Written information is also important, including information sheets, details of web sites, and local support groups. Most powerful is a personalised letter summarising the consultation and giving specific information. Copying the standard clinic letter is a useful alternative. ${ }^{31}$

Patients with chronic conditions are expert in their individual condition ${ }^{32}$ as they constantly live with it. Providing individualised verbal and written information and offering specialist nurse telephone contact encourages greater patient involvement in their long term management.

\section{CONCLUSION}

Epilepsy clinics provide a multidisciplinary focus for the diagnosis and long term management of patients with recurrent blackouts and epilepsy. The diagnosis is clinical rather than investigation based, and the emphasis of management is long term, team delivered, and founded upon a partnership of specialist care with the patient and with primary care, sharing information, supporting and empowering patients, and aiming for their increasing independence.

\section{Authors' affiliations}

S Hadjikoutis, P E M Smith, The Epilepsy Unit, University Hospital of Wales, Cardiff, UK

Conflicts of interest: PS has received hospitality and support from all of the major pharmaceutical companies manufacturing antiepileptic drugs available in the UK.

\section{REFERENCES}

1 National Institute for Health, Clinical Excellence (NICE). Clinical guideline 20. The epilepsies:the diagnosis and management of the epilepsies in adults and children in primary and secondary care-full guideline. hHtp:// www.nice.org.uk/page.aspx?o=229388 (accessed 28 Nov 2004)

2 Smith PEM. If it's not epilepsy... J Neurol Neurosurg Psychiatry 2001;70(suppl):9-14

3 Commission of the International League Against Epilepsy. Recommendation for neuroimaging of patients with epilepsy. Epilepsia 1997;38:1255-6.

4 Brugada A, Geelen P. Some electrocardiographic patterns predicting sudden cardiac death that every doctor should recognise. Acta Cardiol 1997;6:473-84.

5 Brignole M, Alboni P, Benditt D, et al. Task Force on Syncope, European Society of Cardiology. Part 2. Diagnostic tests and treatment: summary of recommendations. Europace 2001;3:261-8.

6 MESS trialists' collaboration. Randomized trial of immediate versus deferred antiepileptic drug treatment of early epilepsy and single seizures. Lancet (in press)

7 Walczak TS, Leppik IE, D'Amelio M, et al. Incidence and risk factors in sudden unexpected death in epilepsy. Neurology 2002;56:519-25.

8 NICE. NICE guidance (technology appraisal) 76. Newer drugs for epilepsy in adults. Issued March 2004. http://www.nice.org.uk/TA076guidance (accessed 29 Nov 2004).

9 Committee on the Safety of Medicines. Sodium valproate and prescribing in pregnancy. Current problems in pharmacovigilance. Committee on the Safety of Medicines 2003;29:6

10 Morrow JI, Russell AJC, Irwin B, et al. The safety of antiepileptic drugs in pregnancy: results of the UK epilepsy and pregnancy register. [Abstract]. Epielpsia 2004;45(suppl 3):57

11 Lawthom C, Smith PEM. What is the role of polytherapy in the management of epilepsy? In: Roberts RC, eds. Better care for children and adults with epilepsy-a consensus conference. J R Coll Physicians Edinb 2003;33(suppl 11):22-30.

12 SANAD. A study of standard and new antiepileptic drugs. http:// www.liv.ac.uk/neuroscience/sanad/ (accessed 29 Nov 2004).

13 Williams J, Myson V, Steward S, et al. Self-discontinuation of antiepileptic medication in pregnancy: detection by hair analysis. Epilepsia 2002;43:824-31

14 Berg AT, Shinnar S. Relapse following discontinuation of antiepileptic drugs: a meta-analysis. Neurology 1994;44:601-8.

15 Chadwick DW representing the MRC Antiepileptic Drug Withdrawal Study Group. Does withdrawal of different anti-epileptic drugs have different effects on seizure recurrence? Brain 1999;122:441-8.

16 Berg AT. Discontinuing antiepileptic drugs. In: Engel J, Pedley TA, eds. Epilepsy: a comprehensive text. New York: Lippincott-Raven, 1997.

17 Spencer SS. When should temporal-lobe epilepsy be treated surgically? Lancet Neurology 2002;1:375-82.

18 Elwes RD. Surgery for temporal lobe epilepsy. BMJ 2002;324:496-7.

19 Engel J Jr. Surgery for seizures. N Engl J Med 1996;334:647-52.

20 NICE. Guidance interventional procedure 50 . Vagus nerve stimulation for refractory epilepsy in children. Issued Mar 2004. http://www.nice.org.uk/ IPG050publicinfo (accessed 29 Nov 2004).

21 Devinsky O. Patients with refractory seizures. N Engl J Med 1999;340:1565-70.

22 Smith PEM, Wallace S. Taking over epilepsy from the paediatric neurologist. J Neurol Neurosurg Psychiatry 2003;74(suppl 1):37-41.

23 Cleary $\mathbf{P}$, Shorvon S, Tallis R. Late-onset seizures as a predictor of subsequent stroke. Lancet 2004;363:1 184-6.

24 Chen-Scarabelli C, Scarabelli TM. Neurocardiogenic syncope. BMJ 2004;329:336-41.

25 DVLA. At a glance; a guide for medical practitioners. http:// www.dvla.gov.uk/at_a_glance/content.htm (accessed 29 Nov 2004).

26 Zahn C. Neurological care of women with epilepsy. Epilepsia 2000;41(suppl):26-31. 
27 Adab N, Jacoby A Smith DF, et al. Additional educational needs in children born to mothers with epilepsy. J Neurol Neurosurg Psychiatry 2001;70:15-21. 28 Dolk H, McElhatton P. Assessing epidemiological evidence for the teratogenic effects of anticonvulsant medications. J Med Genet 2002;39:243-4.

29 Smith DF, Defalla BA, Chadwick DW. The misdiagnosis of epilepsy and the management of refractory epilepsy in a specialist clinic. QJM 1999;92:15-23.
30 Smith PEM Leach JP. Epilepsy: time to review QJM 2003:96:87-9.

31 Smith PEM. Letters to patients: sending the right message. BMJ 2002;324:685

32 Department of Health. The expert patient: a new approach to chronic disease management for the twenty-first century. London: Department of Health, 2001. (http://www.ohn.gov.uk/ohn/people/expert).

\section{bmjupdates+}

bmjupdates+ is a unique and free alerting service, designed to keep you up to date with the medical literature that is truly important to your practice.

bmjupdates+ will alert you to important new research and will provide you with the best new evidence concerning important advances in health care, tailored to your medical interests and time demands.

Where does the information come from?

bmjupdates+ applies an expert critical appraisal filter to over 100 top medical journals A panel of over 2000 physicians find the few 'must read' studies for each area of clinical interest

Sign up to receive your tailored email alerts, searching access and more...

www.bmjupdates.com 